\author{
Loyalitas Kreativitas \\ Aldi Masyarakat Kreatif
}

P-ISSN 2722-2101, E-ISSN 2722-4201

Program Studi Ekonomi Manajemen Universitas Pamulang Jurnal LOKABMAS Kreatif Vol. 01, No. 01, Hal. 25-31

Email:jurnalkreatif.manajemen@gmail.com

\title{
PEMBERDAYAAN IBU-IBU PERUMAHAN DALAM PENGOLAHAN DAN PELUANG USAHA PUPUK KOMPOS PADA BANK SAMPAH SRI REJEKI
}

\author{
Indawati, Anggun Anggraini, Lindawati, Siti Hanah, Wulandarai Cahyani Putri \\ Dosen Ekonomi Fakultas Ekonomi Universitas Pamulang \\ Email dosen02151@unpam.ac.id, dosen02156@unpam.ac.id. Dosen01609@unpam.ac.id, \\ Dosen02248@unpam.ac.id , dosen02274@unpam.ac.id
}

\begin{abstract}
ABSTRAK
Tujuan dari Kegiatan Pengabdian Kepada Masyarakat adalah untuk melaksanakan salah satu Tri Dharma Perguruan Tinggi. Selain itu diharapkan dengan pengabdian kepada masyarakat tersebut keberadaan perguruan tinggi dapat memberikan kontribusi besar kepada pengembangan dan penerapan keilmuan kepada masyarakat.

Kegiatan dalam pelaksanaan pengabdian kepada masyarakat ini dengan tema pemberdayaan ibi-ibu perumahan dalam pengolahan dan peluang usaha pupuk kompos pada bank sampah sri rejeki.. Kegiatan pengabdian yang dilakukan oleh dosen Prodi S1 Akuntansi Universitas Pamulang pada tanggal 21 sampai dengan 23 Juni 2020 disambut baik oleh Para Ibu-ibu perumakasn dan pengurus Bank Sampah. Dengan menggunakan metode penyuluhan dan pelatihan secara daring dengan menggunakan aplikasi Zoom Meeting, kegiatan ini sangat efektif dalam bentuk waktu dan penerimaan materi. Dengan penyuluhan dan pelatihan meraka merespon dengan baik terutama peserta merekapun sangat senang terutapa pada saat penyampaian materi mengenai pembuatan pupuk kompos walaupun bagi mereka ada yang baru pertama kali menggunaka Zoom Meeting intinya mereka sangat antusias dalam penyuluhan yang lakukan oleh para Dosen Unpam.

Target luaran pada program ini adalah publikasi berbagi hasil dari kegiatan ini secara nasional agar dapat dimanfaatkan sebagai literatur dalam bidangnya seperti artikel pada media masa cetak/elektronik, dan peningkatan mutu keberadaan mitra.

Kegiatan ini diharapkan dapat memberikan inspirasi dan motivasi bagi para dosen/peneliti selanjutnya yang akan melakukan kegiatan yang sama/sejenis dan berkelanjutan, ilmu yang diberikan dapat bermanfaat bagi masyarakat, akademisi dan penulis selanjutnya.
\end{abstract}

\section{Kata-kata kunci: Penyuluhan Daring: Pelatihan Daring: Pupuk Kompos: Para Ibu-Ibu Perumahan.}

ABSTRAC

The purpose of Community Service Activities is to carry out one of the Tri Dharma of Higher Education. In addition, it is hoped that with this community service, the existence of universities can make a major contribution to the development and application of science to the community.

Activities in the implementation of this community service with the theme of empowering housing mothers in processing and composting business opportunities at the Sri Rejeki waste bank. The service activities carried out by lecturers of the S1 Accounting Study Program at Pamulang University on June 21 to 23, 2020 were welcomed by The housewives and Waste Bank administrators. By using the extension method and online training using the Zoom Meeting application, this activity is very effective in the form of time and material reception. With 


\section{Loyalitas Kreativitas \\ Aldi Masyarakat Kreatif}

P-ISSN 2722-2101, E-ISSN 2722-4201

Program Studi Ekonomi Manajemen Universitas Pamulang

Jurnal LOKABMAS Kreatif Vol. 01, No. 01, Hal. 25-31

Email:jurnalkreatif.manajemen@gmail.com

counseling and training, they responded well, especially the participants who were very happy especially when delivering material about compost making, even though it was their first time using the Zoom Meeting, in essence, they were very enthusiastic about the counseling carried out by Unpam Lecturers.

The output target of this program is the publication of sharing the results of this activity nationally so that they can be used as literature in their fields such as articles in print / electronic mass media, and improving the quality of partners' existence.

This activity is expected to provide inspiration and motivation for future lecturers / researchers who will carry out the same / similar and sustainable activities, the knowledge provided can be useful for the community, academics and subsequent writers.

Key words: Online Counseling: Online Training: Compost: Residential Mothers.

\section{PENDAHULUAN}

Sampah sudah menjadi masalah yang sangat klasik disekitar kita, masih banyak orang kurang peduli dengan membuang sampah sembarangan atau membiarkannya begitu saja. Ini akan berdampak buruk terhadap lingkungan sekitar kita jika dibiarkan terus menerus. Sampah organik adalah salah satu sampah yang mudah kita manfaatkan menjadi benda yang lebih berguna dan bermanfaat. Karena sampah organik bersifat mudah diurai oleh tanah, berbeda dengan sampah anorganik yang memerlupakan penanganan yang berbeda. Pupuk kompos mungkin sudah sering kita dengar, bahan dasar dari pupuk bisa berasal dari kotoran hewan ternak maupun dari sampah organik yang berupa dedaunan, rumput, sisa hasil pertanian, bahkan sisa sayuran. Pupuk kompos bisa menjadi solusi yang bijak mengingat selain dapat mengurangi dampak sampah organik juga memiliki manfaat yang lebih daripada pupuk kimia.

Menurut data kementrian lingkungan hidup pada tahun 2012 dipaparkan bahwa Undang-Undang Nomor 18 tahun 2008 tentang Pengelolaan Sampah beserta Peraturan Pemerintah Nomor 81 Tahun 2012 mengamanatkan perlunya perubahan paradigma yang mendasar dalam pengelolaan sampah yaitu dari paradigma kumpul - angkut - buang menjadi pengolahan yang bertumpu pada pengurangan sampah dan penanganan sampah. Kegiatan pengurangan sampah bermakna agar seluruh lapisan masyarakat, baik pemerintah, dunia usaha, masyarakat luas melaksanakan kegiatan pembatasan timbulan sampah, pendauran ulang dan pemanfaatan kembali sampah atau yang dikenal dengan sebutan Reduce, Reuse dan Recycle (3R) melalui upaya-upaya cerdas, efsien dan terprogram. Namun kegiatan 3R ini masih menghadapi kendala utama, yaitu rendahnya kesadaran masyarakat untuk memilah sampah. Dengan adanya kegiatan PKM ini terutama dalam memberikan penyuluhan dan pelatihan kepada para Ibu-Ibu dan pengurus Bank Sampah Sri Rejeki dapat meningkatkan pendapatan terutama dalam penjualan pupuk kompos yang dibuat secara sederhana.

Dari uraian pendahuluan diatas, setiap orang memiliki penghasilan dan peningkatan penghasilan demi memenuhi kesejahteraan ekonomi keluarga, meskipun dengan kondisi pandemi Covid19 penghasilan yang menurun harus dapat ditingkatkan. Permasalahan yang dihadapi oleh Mitra yaitu Para Ibu-ibu perumahan dan pengurus Bank Sampah berikut:

Mitra memiliki masalah atas sampah yang ada pada rumah tangga yaitu sampah dapur yang sulit untuk dibuang pada pembuangan akhir.

Tingginya angka sampah yang tidak terkelola dipengaruhi oleh beberapa hal. Pertama, terkait sistem yang memadai untuk 


\section{Loyalitas Kreativitas \\ Aldi Masyarakat Kreatif}

P-ISSN 2722-2101, E-ISSN 2722-4201

Program Studi Ekonomi Manajemen Universitas Pamulang Jurnal LOKABMAS Kreatif Vol. 01, No. 01, Hal. 25-31

Email:jurnalkreatif.manajemen@gmail.com proses pengumpulan sampah. Proses ini biasanya dilakukan para pemulung di jalanan, atau petugas kebersihan yang mengangkat sampah-sampah dari tiap rumah tangga menggunakan truk. Pengumpulan sampah ini dinilai belum optimal, karena belum bisa menjangkau semua sampah. kedua yang patut jadi perhatian adalah perilaku dan kebiasaan masyarakat Indonesia itu sendiri, yang sering membuang sampah langsung ke sungai atau ke alam.

Edukasi kesadaraan dan keterampilan warga untuk pengelolaan sampah penting dalam penyelesaian masalah sampah melalui pengelolaan sampah sejak dari sumbernya. Untuk merubah paradigma masyarakat mengenai sampah dan perlu dilakukan secara berkelanjutan. Bank sampah yang berbasiskan partisipasi masyarakat merupakan solusi dalam pengelolaan sampah berbasis masyarakat.

Pemberdayaan warga dalam pengelolaan sampah dapat dilakukan melalui kegiatan penyuluhan, edukasi, pelatihan dengan metode partisipasi emansipatoris (interaksi dan komunikasi), serta dialog dengan warga di komunitas. Selain itu diperlukan dukungan kemitraan dengan membangun jejaring dan mekanisme kerjasama kelembagaan antara warga pengelola bank sampah dengan stakeholder terkait. Berdasarkan uraian di atas maka dirasa penting untuk melakukan sutau kegiatan pengabdian dalam bentuk pemberdayan masyarakat dalam pengelolaan sampah organik.

\section{RUMUSAN MASALAH}

Dengan mempertimbangkan latar belakang yang telah diutarakan diatas kami berinisiatif untuk membentuk pengabdian masyarakat bagi para Ibu-Ibu dan pengurus Bank Sampah Sri Rejeki dengan masalah yang dihadapi oleh mitra, maka disepakati bahwa masalah utama yang dihadapi antara lain:
1. Pentingnya penanganan masalah atas sampah pada rumah tangga,

2. Pentingnya pengetahuan dalam pengolahan sampah dan kesadaran atas lingkungan.

\section{TUJUAN PELAKSANAAN}

Edukasi kesadaraan dan keterampilan warga untuk pengelolaan sampah penting dalam penyelesaian masalah sampah melalui pengelolaan sampah sejak dari sumbernya. Untuk merubah paradigma masyarakat mengenai sampah dan perlu dilakukan secara berkelanjutan. Bank sampah yang berbasiskan partisipasi masyarakat merupakan solusi dalam pengelolaan sampah berbasis masyarakat.

Pemberdayaan warga dalam pengelolaan sampah dapat dilakukan melalui kegiatan penyuluhan, edukasi, pelatihan dengan metode partisipasi emansipatoris (interaksi dan komunikasi), serta dialog dengan warga di komunitas. Selain itu diperlukan dukungan kemitraan dengan membangun jejaring dan mekanisme kerjasama kelembagaan antara warga pengelola bank sampah dengan stakeholder terkait. Berdasarkan uraian di atas maka dirasa penting untuk melakukan sutau kegiatan pengabdian dalam bentuk pemberdayan masyarakat dalam pengelolaan sampah organik.

\section{TINJAUAN PUSTAKA}

Berdasarkan data Kementerian Lingkungan Hidup dan Kehutanan menjelaskan bahwa sampah di Indonesia akan mencapai 68 juta tons. Menteri Lingkungan Hidup dan Kehutanan Siti Nurbaya Bakar, M.Sc. mengatakan jenis sampah yang dihasilkan didominasi oleh sampah organik yang mencapai sekitar 60 persen dan sampah plastik yang mencapai 15 persen. Persoalan pengelolaan sampah menjadi pekerjaan rumah besar bagi Indonesia. Riset terbaru Sustainable Waste Indonesia (SWI) mengungkapkan sebanyak 24 persen sampah di Indonesia masih tidak terkelola.

Bank sampah lahir dari program 


\section{Loyalitas Kreativitas \\ Aldi Masyarakat Kreatif}

P-ISSN 2722-2101, E-ISSN 2722-4201

Program Studi Ekonomi Manajemen Universitas Pamulang Jurnal LOKABMAS Kreatif Vol. 01, No. 01, Hal. 25-31

Email:jurnalkreatif.manajemen@gmail.com
Jakarta Green and Clean yaitu salah satu cara pengelolaan sampah skala rumah tangga, yang menitik beratkan pada pemberdayaan masyarakat dalam mengelola sampah rumah tangga. Bank sampah adalah tempat menabung sampah yang telah terpilih menurut jenis sampah, sampah yang ditabung pada bank sampah adalah sampah yang mempunyai nilai ekonomis. Cara kerja bank sampah pada umumnya hampir sama dengan bank lainnya, ada nasabah, pencatatan pembukuan dan manajemen pengelolaannya, apabila dalam bank yang biasa kita kenal yang disetorkan nasabah adalah uang akan tetapi dalam bank sampah yang disetorkan adalah sampah yang mempunyai nilai ekonomis, sedangkan pengelola bank sampah harus orang kreatif dan inovatif serta memiliki jiwa kewirausahaan agar dapat meningkatkan pendapatan masyarakat. Sistem kerja bank sampah pengelolaan sampahnya berbasis rumah tangga, dengan memberikan reward kepada yang berhasil memilah dan menyetorkan sejumlah sampah (Unilever Green\&Clean, 2010).

Konsep bank sampah ini menjadi salah satu solusi bagi pengelolaan sampah di Indonesia yang masih bertumpu pada pendekatan akhir. Dengan program ini, sampah mulai dikelola dari awal sumber timbunan sampah, yaitu rumah tangga. Pemilihan yang dilakukan oleh masyarakat sejak awal membuat timbunan sampah yang dihasilkan dan dibawa ke tempat pembuangan akhir (TPA) menjadi berkurang (Medan Green\&Clean, 2010).

Pengertian pengolahan dari sampah organik yang akan dijadikan pupuk kompos, Kompos adalah jenis pupuk yang berasal dari bahan-bahan organik atau sisa-sisa makhluk hidup, baik dari tumbuhan maupun hewan. Bahan organik ini lalu mengalami dekomposisi atau pembusukan dengan bantuan organisme pengurai. Karena dibuat dari bahan organik dengan proses alami, kompos sering dianggap sebagai pupuk terbaik untuk tanaman. Kompos memiliki banyak manfaat di bidang pertanian. Secara garis besar, kompos punya manfaat yang sama seperti jenis pupuk lainnya, yaitu membantu kesuburan tanaman.

Konsep bank sampah ini tidak jauh berbeda dengan konsep 3R (Reduse, Reuse, Recycle). Jika dalam konsep 3R ditekankan bagaimana agar mengurangi jumlah sampah yang ditimbulkan dengan menggunakan atau mendaur ulangnya, dalam konsep bank sampah ini, paling ditekankan adalah bagaimana agar sampah yang sudah dianggap tidak berguna dan tidak memiliki manfaat dapat memberikan manfaat tersendiri dalam bentuk uang, sehingga masyarakat termotivasi untuk memilah sampah yang mereka hasilkan. Proses pemilahan inilah yang mengurangi jumlah timbunan sampah yang dihasilkan dari rumah tangga sebagai penghasil sampah terbesar di perkotaan. Konsep Bank Sampah membuat masyarakat sadar bahwa sampah memiliki nilai jual yang dapat menghasilkan uang, sehingga mereka peduli untuk mengelolanya, mulai dari pemilahan, pengomposan, hingga menjadikan sampah sebagai barang yang bisa digunakan kembali dan bernilai ekonomis (Aryenti, 2011).

Peran Bank Sampah terdapat dalam teori pertukaran. "Teori pertukaran menekankan kepada sosiologi perilaku agar memusatkan perhatian pada hubungan antara pengaruh perilaku seorang aktor terhadap lingkungan dan dampak lingkungan terhadap aktor. Hubungan ini adalah dasar untuk pengkondisian operan atau proses belajar yang melalui perilaku disebabkan oleh konsekuensinya."(Ritzer dan Douglas, 2007). Teori ini berkembang pada rewadsand punishment. Bank sampah merupakan institusi lokal yang kekuasaannya tidak begitu besar. Bank Sampah tidak dapat melakukan punishment kepada masyarakat, sehingga Bank Sampah harus menggunakan sistem rewads. Proses penyadaran lingkungan melalui tabungan sampah yang dinilai dengan uang atau Rupiah merubah paradigma masyarakat tentang sampah. Sampah yang seharusnya dibuang menjadi bermanfaat. 


\section{Loyalitas Kreativitas \\ Aldi Masyarakat Kreatif}

P-ISSN 2722-2101, E-ISSN 2722-4201

Program Studi Ekonomi Manajemen Universitas Pamulang Jurnal LOKABMAS Kreatif Vol. 01, No. 01, Hal. 25-31

Email:jurnalkreatif.manajemen@gmail.com

\section{HASIL DAN PEMBAHASAN}

Proses Pengelolaan Sampah Menjadi Pupuk Kompos:

1. Mekanisme Pengolahan Sampah

Adapun mekanisme pengelolaan sampah di Bank Sampah Griya Asri sebagai berikut:

1) Nasabah mempunyai sampah rumah tangga yang akan di tabung di bank Sampah Sri Rejeki

2) Nasabah melakukan Pemilahan dan pembersihan sampah yang nantinya akan dibawa ke Bank Sampah Jati Asri. pemilihan dilakukan dengan cara memisahkan sampah berdasarkan jenisnya. Karena setiap sampah memiliki harga yang berbedabeda.

3) Sampah yang telah di pilah ditimbang oleh petugas bank sampah jati sri rejeki berdasarkan jenisnya. setiap sampah memiliki harga yang berbeda berdasarkan jenisnya.

4) Hasil timbangan sampah di catat dalam buku milik petugas bank sampah jati asri dan buku tabungan milik nasabah yang didalamnya berupa pencatatan jumlah uang yang didapat oleh nasabah.

5) Sampah dari nasabah di simpan dalam gudang penyimpanan Bank Sampah.

6) Kumpulan sampah dari nasabah yang terkumpul akan diambil untuk didaur ulang oleh bank sampah sesuai kebutuhan.

7) Sampah yang tidak memungkinkan untuk didaur ulang akan di jual ke pengepul.

8) Hasil daur ulang bank sampah di pasarkan dan dijual untuk umum. Sehingga sampah kembali digunakan oleh masyarakat.

2. Dampak ekonomi masyarakat

Bank Sampah Sri Rejeki telah mengubah persepsi bahwa sampah adalah barang yang tidak berguna bisa menjadi sesuatu yang bernilai ekonomis. Hal ini telah menarik masyarakat untuk bergabung dalam kegiatan yang dilakukan oleh Bank Sampah Griya Asri baik dengan mengumpulkan sampah untuk di setorkan ataupun terlibat langsung dalam proses pengelolaan sampah (daur ulang). Pemberdayaan yang dilakukan bank sampah terhadap masyarakat hasilnya adalah tentang bagaimana bank sampah dapat meningkatkan pendapatan yang ada di masyarakat sehingga dapat memenuhi kebutuhan mereka. Masyarakat yang menjadi anggota Bank Sampah Griya Asri telah mendapatkan dampak berupa peningkatan pendapatan.

3. Dampak Sosial Masyarakat

Tujuan akhir pemberdayaan adalah adanya peningkatan pendapatan Indikator keberhasilan pemberdayaan masyarakat sebagai sebuah proses seringkali diambil dari tujuan sebuah pemberdayaan yang menunjukan pada keadaan atau hasil yang ingin dicapai oleh sebuah perubahan sosial.

Kegiatan Pengabdian Masyarakat Universitas Pamulang yang dilakukan oleh dosen-dosen program studi Akuntansi telah berjalan dengan lancar dan mendapat sambutan hangat dari tempat pelaksanaan kegiatan ini.

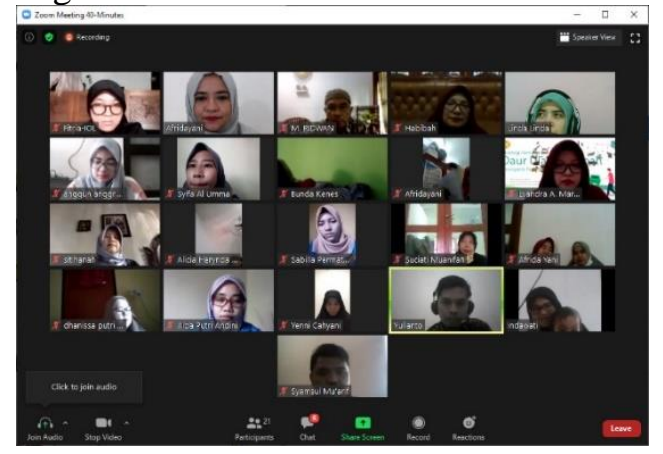

Harapan kami dengan pengabdian ini adalah meningkatnya pengetahuan dan kemampuan para Ibu-ibu dalam mengolah dan mendapatkan keuntungan dengan pengolahan dan pengelolaan sampah organic menjadi kompos. 


\section{Loyalitas Kreativitas \\ Aldi Masyarakat Kreatif}

P-ISSN 2722-2101, E-ISSN 2722-4201

Program Studi Ekonomi Manajemen Universitas Pamulang Jurnal LOKABMAS Kreatif Vol. 01, No. 01, Hal. 25-31

Email:jurnalkreatif.manajemen@gmail.com

\section{KESIMPULAN DAN SARAN \\ Kesimpulan}

Dari paparan yang sudah kami bahas diatas, berikut adalah kesimpulan yang dapat dipaparkan:

1. Pelaksanaan kegiatan Pengabdian Kepada Masyarakat yang dilakukan oleh dosendosen program studi Akuntansi telah berjalan dengan lancar dan mendapat sambutan hangat dari tempat pelaksanaan kegiatan ini yaitu Bank Sampah Sri Rejeki yang beralamat di Jl. Borobudur 1 blok C.26 No:5 Rt 01/04 Serua Permai, Benda Baru, Pamulang- Tangerang Selatan. Tema/Judul yang akan disampaikan dalam pengabdian kepada masyarakat ini yaitu "Pemberdayaan Ibu-Ibu Perumahan dalam Pengolahan dan Peluang Usaha Pupuk Kompos Pada Bank Sampah Sri Rejeki".

2. Dengan diadakannya program Pengabdian Kepada Masyarakat ini, pengurus dan masyarakat sekitar, dapat menjalankan program untuk memasarkan dengan harga jual yang lebih efektif. Sehingga dari sampah yang tadinya terbuang akan menghasilkan keuntungan dan membantu perekonomian rumah tangga warga sekitar.

\section{Saran}

Dengan adanya program Pengabdian Kepada Masyarakat ini, semoga bank sampah beserta masyarakat dapat bersinergi dalam pengelolaan sampah dan mengembangkan produk produk untuk dapat dijual kembali, dan lebih menginspirasi bagi bank sampah lainnya di wilayah Tangerang Selatan pada umumnya.

\section{DAFTAR PUSTAKA}

Mukono HJ. Prinsip Dasar Kesehatan Lingkungan Surabaya: Airlangga University Press; 2006.

\begin{tabular}{|c|c|}
\hline $\begin{array}{l}\text { Notoatmodjo, } \\
\text { Pengembangan }\end{array}$ & $\begin{array}{l}\text { Soekidjo, } \\
\text { Sumber }\end{array}$ \\
\hline
\end{tabular}

Pasaribu, V. L. D., Susanti, F., \& Hartuti, E. T. K. (2019). Memotivasi Siswa dan Siswi SMK Letris Indonesia di Dalam Menentukan Pilihan Untuk Melanjutkan Pendidikan Atau Bekerja Setelah Lulus Sekolah. Jurnal Pengabdian Dharma Laksana, 1(2), 161172.

Pasaribu, V. L. D., Elburdah, R. P., Sudarso, E., \& Fauziah, G. (2020). PENGGUNAAN MANAJEMEN WAKTU TERHADAP PENINGKATAN PRESTASI BELAJAR DI SMP ARAISIYAH. Jurnal ABDIMAS Tri Dharma Manajemen, 1(1).

Pasaribu, V. L. D., Agrasadya, A., Shabrina, N., \& Krisnaldy, K. (2020). MENJADI ENTERPRENEUR MUDA YANG MEMILIKI JIWA LEADERSHIP UNTUK MENGHADAPI MASA DEPAN. Abdi Laksana, 1(1).

Pasaribu, V. L. D., Sulaiman, S., Sutiman, S., Thaharudin, T., \& Purnomo, B. Y. (2020). PENGENALAN LETAK POSYANDU TERDEKAT DIKELURAHAN PISANGAN DENGAN MANAJEMEN PEMASARAN REVOLUSI 4.0 UNTUK MENINGKATKAN PENGETAHUAN MASYARAKAT LETAK DAN FUNGSI POSYANDU TERDEKAT PADA KELURAHAN PISANGAN. DEDIKASI PKM, 1(1), 105-110.

Priadi, A., Pasaribu, V. L. D., Virby, S., Sairin, S., \& Wardani, W. G. (2020). PENGUATAN EKONOMI KREATIF BERBASIS SUMBER DAYA DESA DIKELURAHAN REMPOA. Abdi Laksana, 1(3), 356-358.

Slamet J.S. 2009. Kesehatan Lingkungan. Yogyakarta: Gajah Mada University Press.

Sujarweni V. Wiratna, (2015), Akuntansi Manajemen Teori dan Aplikasi. Yogyakarta : Pustaka Baru Press.

Pemerintah Indonesia. Undang-undang No.81 Tahun 2012 tentang Pengelolaan Sampah Rumah Tangga dan Sampah Sejenis. Lembaran Negara RI Tahun 2012. Sekretariat Negara. Jakarta. 
Loyalitas Kreativitas

Aldi Masyarakat Kreatif
P-ISSN 2722-2101, E-ISSN 2722-4201

Program Studi Ekonomi Manajemen Universitas Pamulang Jurnal LOKABMAS Kreatif Vol. 01, No. 01, Hal. 25-31

Email:jurnalkreatif.manajemen@gmail.com

Pemerintah Indonesia. Undang-undang

Nomor 32 Tahun 2009 Tentang

Perlindungan dan Pengelolaan

Lingkungan Hidup. Lembaran Negara

RI Tahun 2012. Sekretariat Negara.

Jakarta.

https://softwareaccurate.id/aplikasi-

akuntansi-pembukuan-keuangan-

gratis.

\section{DOKUMENTASI KEGIATAN}

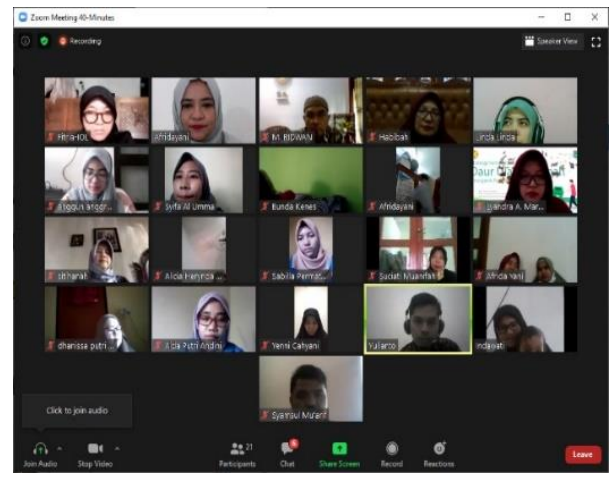

Gambar 1. Ketua Pelaksana Pengabdian

Kepada Masyarakat memberikan kata sambutan dan membuka acara PKM sekaligus memaparkan materi PKM.

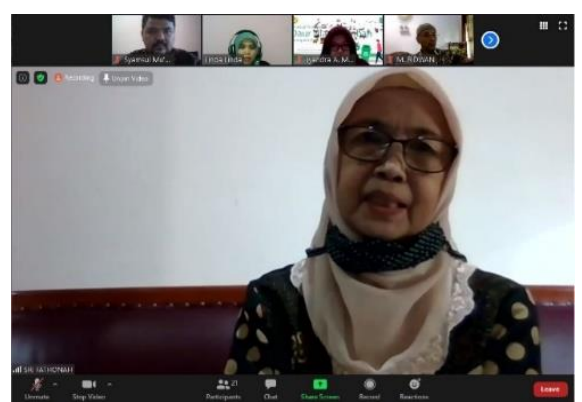

Gambar 2. Sambutan Ketua Bank Sampah Sri Rejeki

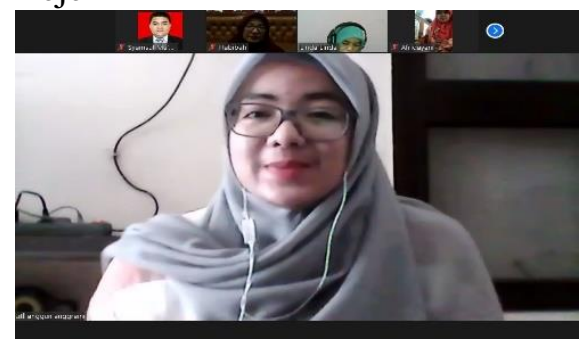

Gambar 3. Narasumber 